\title{
Coincidence point results via generalized $(\psi, \phi)$-weak contractions in partial ordered b-metric spaces with application
}

\author{
Muhammad Sarwar ${ }^{\mathrm{a}}$, Noor Jamal ${ }^{\mathrm{a}}$, Yongjin Lij,* \\ ${ }^{a}$ Department of Mathematics, University of Malakand, Chakdara Dir(L), Pakistan. \\ ${ }^{b}$ Department of Mathematics, Sun Yat-sen University, Guangzhou, 510275, P. R. China. \\ Communicated by F. Vetro
}

\begin{abstract}
In this manuscript, some coincidence point and fixed point results via generalized $(\psi, \phi)$-weak contractive condition are established. The presented work explicitly generalize some recent results from the existing literature in the setting of partial order b-metric spaces. An example is provided to show the authenticity of the derived results. (c)2017 All rights reserved.
\end{abstract}

Keywords: Generalized $(\psi, \phi)$-weak contraction, coincidence point, weak compatible mapping, increasing pairs of maps, partial ordered complete b-metric spaces.

2010 MSC: $47 \mathrm{H} 10,54 \mathrm{H} 25$.

\section{Introduction and preliminaries}

Metric fixed point theory is one of the most interesting research area in the development of non-linear analysis. In this field the first significant result was proved by Banach, known as Banach contraction principle. This principle has been generalized by a lot of authors either by changing the contractive condition or by changing the underlying spaces, one of these generalizations is $(\psi, \phi)$-weak contraction. The $(\psi, \phi)$-weak contraction and generalized $(\psi, \phi)$-weak contraction have been used in many papers for the study of fixed point in complete metric spaces. Some of these valuable works are noted in $[1,7,8,13]$.

Partial order metric spaces are the interesting generalization of metric spaces, which was introduced by Ran and Reurings [16] for the existence of fixed point. Using $(\psi, \phi)$-weak contraction, coincidence point and fixed point results are established by many authors in partial ordered b-metric spaces (for detail see $[14,15,17,18,22])$.

Presently, the study of $(\psi, \phi)$-weak contraction in partial ordered b-metric spaces gain the attraction of many researchers. In this direction fixed point results, coincidence point results and their application to the solution of linear and nonlinear integral equations are investigated (see [3, 4, 19-21] and the reference cited therein).

\footnotetext{
*Corresponding author

Email addresses: sarwarswati@gmail.com (Muhammad Sarwar), noorjamalmphil791@gmail .com (Noor Jamal), stslyj@mail. sysu. edu.cn (Yongjin Li)
}

doi:10.22436/jnsa.010.07.29 
In the current work, coincidence point results for compatible and weakly increasing mappings in partial ordered complete b-metric spaces with $(\psi, \phi)$-weak contractive conditions are studied. The derived results generalize some well-known results from the existing literature.

Definition 1.1 ([2]). Let $G, H: Y \rightarrow Y$ be two mappings on the partial order set $Y$. The pair of mappings $(\mathrm{G}, \mathrm{H})$ is called:

(1) weakly increasing if $\mathrm{Gu} \preceq \mathrm{H}(\mathrm{Gu})$ and $\mathrm{Hu} \preceq \mathrm{G}(\mathrm{Hu})$ for all $u \in \mathrm{Y}$;

(2) partially weakly increasing if for all $u \in Y, G u \preceq H(G u)$.

Definition $1.2([9,14])$. Let $G, H, L: Y \rightarrow Y$ be three mappings on partial order set $(Y, \preceq)$ such that $\mathrm{Gu} \subseteq \mathrm{Lu}$ and $\mathrm{Hu} \subseteq \mathrm{Lu}$. The pair of mappings $(\mathrm{G}, \mathrm{H})$ is called:

(i) weakly increasing with respect to $L$ if and only if for all $u \in Y, G u \preceq H w$ for all $w \in L^{-1}(G u)$ and $\mathrm{Hu} \preceq \mathrm{G} w$ for all $w \in \mathrm{L}^{-1}(\mathrm{Hu})$;

(ii) partially weakly increasing with respect to $\mathrm{L}$ if and only if $\mathrm{Gu} \preceq \mathrm{H} w$ for all $w \in \mathrm{L}^{-1}(\mathrm{Gu})$.

Definition 1.3 ([11]). Let $G, H: Y \rightarrow Y$ be two mappings on metric space $\left(Y, d_{1}\right)$. A pair of mappings $(G, H)$ is compatible if and only if

$$
\lim _{m \rightarrow \infty} d\left(G H u_{m}, H G u_{m}\right)=0,
$$

whenever $\left\{u_{m}\right\}$ is a sequence such that

$$
\lim _{m \rightarrow \infty} G u_{m}=\lim _{m \rightarrow \infty} H u_{m}=r \text { with } r \in Y .
$$

Definition 1.4 ([12]). Let $G, H: Y \rightarrow Y$ be two mappings on metric space $\left(Y, d_{1}\right)$. A pair of mappings $(G, H)$ is said to be weakly compatible if they commute at coincidence points, that is, if $\mathrm{Gu}=\mathrm{Hu}$ for some $u \in Y$, then $\mathrm{HGu}=\mathrm{GHu}$.

Definition 1.5 ([6]). Let $Y$ be a nonempty set and the mapping $d_{1}: Y \times Y \rightarrow \mathbf{R}^{+}$satisfies:

$\left.b_{1}\right) d_{1}(p, q)=0$ if and only if $p=q$;

$\left.b_{2}\right) d_{1}(p, q)=d_{1}(q, p)$;

$\left.b_{3}\right)$ there exists a real number $s \geqslant 1$ such that $d_{1}(p, r) \leqslant s\left(d_{1}(p, q)+d_{1}(q, r)\right)$ for all $p, q, r \in Y$.

Then $d_{1}$ is a b-metric while the pair $\left(Y, d_{1}\right)$ is called b-metric space. If $d_{1}$ is defined on a partial order set $(Y, \preceq)$, then such a b-metric space is called partial order b-metric space.

Definition 1.6 ([5]). A sequence $\left\{u_{m}\right\}$ is called b-Cauchy in a b-metric space $\left(Y, d_{1}\right)$ if and only if

$$
\lim _{m, n \rightarrow \infty} d_{1}\left(u_{m}, u_{n}\right)=0 .
$$

Definition $1.7([5])$. A sequence $\left\{w_{m}\right\}$ is called $b$-convergent in a b-metric space $\left(Y, d_{1}\right)$ if and only if there exists $w \in Y$ such that $\lim _{m \rightarrow \infty} \mathrm{d}\left(w_{\mathrm{m}}, w\right)=0$.

Definition 1.8 ([20]). A partial order b-metric space $(Y, d \preceq)$ is said to be regular if the following conditions are satisfied:

(i) if non-decreasing sequence $w_{m} \rightarrow w$ then $w_{m} \preceq w$ for all $\mathrm{m}$;

(ii) if non-increasing sequence $u_{m} \rightarrow u$ then $u_{m} \succeq u$ for all $\mathrm{m}$.

In what follows, we shall make use of the following lemma.

Lemma 1.9 ([10]). Let $\left\{w_{\mathrm{m}}\right\}$ be a sequence in $\mathrm{b}$-metric space $\left(\mathrm{Y}, \mathrm{d}_{1}\right)$ and $\mathrm{s} \geqslant 1$ such that,

$$
\mathrm{d}_{1}\left(w_{\mathrm{m}}, w_{\mathrm{m}+1}\right) \leqslant \mathbb{k}_{1}\left(w_{\mathrm{m}-1}, w_{\mathrm{m}}\right)
$$

for some $\mathbb{k}, 0<\mathbb{k}<\frac{1}{\mathrm{~s}}$, for $\mathrm{m}=1,2, \cdots$. Then $\left\{w_{\mathrm{m}}\right\}$ is a Cauchy sequence in $\left(\mathrm{Y}, \mathrm{d}_{1}\right)$. 
In [20], the authors proved the following theorem with $M(x, y)$ define by

$$
M(x, y) \in\left\{d(S x, R y), \frac{d(S x, f x)+d(R y, g y)}{2 s}, \frac{d(S x, g y)+d(R y, f x)}{2 s^{2}}\right\}
$$

for all $x, y \in X$.

Theorem 1.10. Let $(X, \preceq, d)$ be a partial ordered complete b-metric space and $f, g, R, S: X \rightarrow X$ be four mappings such that $f(X) \subseteq R(X)$ and $g(X) \subseteq S(X)$. Suppose that for every $x, y \in X$ with comparable elements $S x, R y$, the following condition holds

$$
\psi\left(s^{4} d_{1}(f x, g y)\right) \leqslant \psi(M(x, y))-\phi(M(x, y)) \text { for all } x, y \in X,
$$

where $\phi, \psi:[0, \infty) \rightarrow[0, \infty)$ are altering distance functions. Let $f, g, R, S: X \rightarrow X$ be continuous mappings, let $(\mathrm{f}, \mathrm{S})$ and $(\mathrm{g}, \mathrm{R})$ be compatible pairs and let $(\mathrm{f}, \mathrm{g})$ and $(\mathrm{g}, \mathrm{f})$ be partially weakly increasing pairs with respect to $\mathrm{R}$ and $S$, respectively. Then the pairs $(f, S)$ and $(g, R)$ have a coincidence point $z$ in $X$. Moreover, if $R z$ and $S z$ are comparable then $z$ is coincidence point of $f, g, R$, and $S$.

\section{Main results}

In this section, we generalize some recent coincidence point results in partial order complete b-metric spaces under generalized $(\psi, \phi)$-weak contraction. Throughout the paper, for all $u, w \in Y$ and $\alpha \geqslant 1$,

$$
M(u, w) \in\left\{d_{1}(L u, J w), \frac{d_{1}(L u, G u)+d_{1}(J w, H w)}{2 s^{\alpha-1}}, \frac{d_{1}(L u, H w)+d_{1}(J w, G u)}{2 s^{\alpha}}\right\} .
$$

Here, $\mathbf{R}^{+}$is the set of positive real numbers.

Theorem 2.1. Let $\mathrm{G}, \mathrm{H}, \mathrm{L}, \mathrm{J}: \mathrm{Y} \rightarrow \mathrm{Y}$ be continuous mappings on a partial ordered complete $\mathrm{b}$-metric space $\left(\mathrm{Y}, \preceq, \mathrm{d}_{1}\right)$ such that $\mathrm{G}(\mathrm{Y}) \subseteq \mathrm{J}(\mathrm{Y})$ and $\mathrm{H}(\mathrm{Y}) \subseteq \mathrm{L}(\mathrm{Y})$. Assume that for $\epsilon>1$ the compatible pairs $(\mathrm{G}, \mathrm{L})$ and $(\mathrm{H}, \mathrm{J})$ satisfy the contractive condition

$$
\psi\left(s^{\epsilon} d_{1}(G u, H w)\right) \leqslant \psi(M(u, w))-\phi(M(u, w)) \text { for all } u, w \in Y,
$$

whenever $\phi, \psi:[0, \infty) \rightarrow[0, \infty)$ are altering distance functions and the pairs $(\mathrm{G}, \mathrm{H})$ and $(\mathrm{H}, \mathrm{G})$ are partially weakly increasing with respect to $\mathrm{J}$ and $\mathrm{L}$, respectively. Then the pairs $(\mathrm{G}, \mathrm{L})$ and $(\mathrm{H}, \mathrm{J})$ have a coincidence point. Further, if $\mathrm{L} w$ and $\mathrm{Jw}$ are comparable then $w$ is coincidence point of $\mathrm{G}, \mathrm{H}, \mathrm{J}$, and $\mathrm{L}$.

Proof. Let $u_{0}$ be an arbitrary point of $Y$. Since $G(Y) \subset J(Y)$ and $H(Y) \subset L(Y)$, there exist $u_{1}, u_{2} \in Y$ such that $\mathrm{Gu}_{0}=J u_{1}$ and $H u_{1}=L u_{2}$. Construct a sequence $\left\{w_{m}\right\}$ defined by

$$
w_{2 m+1}=\mathrm{Gu}_{2 m}=\mathrm{Ju}_{2 \mathrm{~m}+1}, \quad w_{2 \mathrm{~m}+2}=\mathrm{Hu}_{2 \mathrm{~m}+1}=\mathrm{Lu}_{2 \mathrm{~m}+2}, \quad \text { for } \mathrm{m}=0,1,2, \cdots .
$$

As $(G, H)$ and $(H, G)$ are partially weakly increasing with respect to $J$ and $L$, respectively, we have $\mathrm{u}_{1} \in \mathrm{J}^{-1}\left(\mathrm{Gu}_{0}\right)$ and $\mathrm{u}_{2} \in \mathrm{L}^{-1}\left(\mathrm{Hu} \mathrm{u}_{1}\right)$. Thus

$$
\mathrm{Ju}_{1}=\mathrm{Gu}_{0} \preceq \mathrm{Hu} \mathrm{u}_{1}=\mathrm{Lu}_{2} \preceq \mathrm{Gu}_{2}=\mathrm{Ju}_{3} .
$$

Repeating this process, we obtain

$$
\mathcal{W}_{2 m+1} \preceq \mathcal{w}_{2 m+2} \text {, for all } \mathrm{m} \in \mathrm{N} \cup\{0\} .
$$

Without loss of generality, we can assume that

$$
w_{\mathrm{m}} \neq w_{\mathrm{m}+1} \text { for all } \mathrm{m} \in \mathrm{N} .
$$

We will complete the proof in three steps. 
Step I. We will prove that $d_{1}\left(w_{2 m+1}, w_{2 m}\right) \leqslant d_{1}\left(w_{2 m}, w_{2 m-1}\right)$.

Since $L u_{2 m}=w_{2 m}$ and $J u_{2 m+1}=w_{2 m+1}$ are comparable, from (2.1) we have

$$
\psi\left(s^{\epsilon} d_{1}\left(w_{2 m+1}, w_{2 m}\right)\right)=\psi\left(s^{\epsilon} d_{1}\left(G u_{2 m}, H u_{2 m-1}\right)\right) \leqslant \psi\left(M\left(u_{2 m}, u_{2 m-1}\right)\right)-\phi\left(M\left(u_{2 m}, u_{2 m-1}\right)\right)
$$

with

$$
\begin{aligned}
& M\left(u_{2 m}, u_{2 m-1}\right) \\
& \quad \in\left\{d_{1}\left(w_{2 m}, w_{2 m-1}\right), \frac{d_{1}\left(w_{2 m}, w_{2 m+1}\right)+d_{1}\left(w_{2 m-1}, w_{2 m}\right)}{2 s^{\alpha-1}}, \frac{d_{1}\left(w_{2 m}, w_{2 m}\right)+d_{1}\left(w_{2 m-1}, w_{2 m+1}\right)}{2 s^{\alpha}}\right\}, \\
& M\left(u_{2 m}, u_{2 m-1}\right) \\
& \quad \in\left\{d_{1}\left(w_{2 m}, w_{2 m-1}\right), \frac{d_{1}\left(w_{2 m}, w_{2 m+1}\right)+d_{1}\left(w_{2 m-1}, w_{2 m}\right)}{2 s^{\alpha-1}}, \frac{d_{1}\left(w_{2 m+1}, w_{2 m-1}\right)}{2 s^{\alpha}}\right\} .
\end{aligned}
$$

Assume that $\mathrm{d}_{1}\left(w_{2 m-1}, w_{2 m}\right)<\mathrm{d}_{1}\left(w_{2 m}, w_{2 m+1}\right)$. We have the following three possible cases.

Case (1): $M\left(u_{2 m}, u_{2 m-1}\right)=d_{1}\left(w_{2 m}, w_{2 m-1}\right)$. Then

$$
\psi\left(s^{\epsilon} d_{1}\left(w_{2 m}, w_{2 m+1}\right)\right) \leqslant \psi\left(d_{1}\left(w_{2 m}, w_{2 m-1}\right)\right)-\phi\left(d_{1}\left(w_{2 m}, w_{2 m-1}\right)\right) \leqslant \psi\left(d_{1}\left(w_{2 m}, w_{2 m-1}\right)\right) .
$$

Since $\psi$ is non-decreasing, one has

$$
s^{\epsilon} d_{1}\left(w_{2 m}, w_{2 m+1}\right) \leqslant d_{1}\left(w_{2 m}, w_{2 m-1}\right),
$$

a contradiction. We conclude that $d_{1}\left(w_{2 m+1}, w_{2 m}\right) \leqslant d_{1}\left(w_{2 m}, w_{2 m-1}\right)$.

Case (2): $M\left(u_{2 m}, u_{2 m-1}\right)=\frac{d_{1}\left(w_{2 m}, w_{2 m+1}\right)+d_{1}\left(w_{2 m-1}, w_{2 m}\right)}{2 s^{\alpha-1}}$.

Since $\frac{d_{1}\left(w_{2 m}, w_{2 m+1}\right)+d_{1}\left(w_{2 m-1}, w_{2 m}\right)}{2 s^{\alpha-1}} \leqslant \frac{d_{1}\left(w_{2 m+1}, w_{2 m}\right)}{s^{\alpha-1}}$, we have

$$
\begin{aligned}
\psi\left(s^{\epsilon} d_{1}\left(w_{2 m}, w_{2 m+1}\right)\right) & \leqslant \psi\left(\frac{d_{1}\left(w_{2 m}, w_{2 m+1}\right)}{s^{\alpha-1}}\right)-\phi\left(\frac{d_{1}\left(w_{2 m}, w_{2 m+1}\right)+d_{1}\left(w_{2 m-1}, w_{2 m}\right)}{2 s^{\alpha-1}}\right) \\
& \leqslant \psi\left(s^{\epsilon} d_{1}\left(w_{2 m+1}, w_{2 m}\right)\right)-\phi\left(\frac{d_{1}\left(w_{2 m}, w_{2 m+1}\right)+d_{1}\left(w_{2 m-1}, w_{2 m}\right)}{2 s^{\alpha-1}}\right) .
\end{aligned}
$$

This is only possible if

$$
\phi\left(\frac{d_{1}\left(w_{2 m}, w_{2 m+1}\right)+d_{1}\left(w_{2 m-1}, w_{2 m}\right)}{2 s^{\alpha-1}}\right) \leqslant 0 .
$$

By $\phi$ is altering distance function, we obtain

$$
\frac{\mathrm{d}_{1}\left(w_{2 \mathrm{~m}}, w_{2 \mathrm{~m}+1}\right)+\mathrm{d}_{1}\left(w_{2 \mathrm{~m}-1}, w_{2 \mathrm{~m}}\right)}{2 \mathrm{~s}^{\alpha-1}}=0 .
$$

Hence $d_{1}\left(w_{2 m}, w_{2 m+1}\right)=0$. That is, $w_{2 m}=w_{2 m+1}$, a contradiction to (2.2). Hence $d_{1}\left(w_{2 m+1}, w_{2 m}\right) \leqslant$ $\mathrm{d}_{1}\left(w_{2 \mathrm{~m}}, w_{2 \mathrm{~m}-1}\right)$.

Similarly, it can be proved for third case that,

$$
d_{1}\left(w_{2 m+1}, w_{2 m}\right) \leqslant d_{1}\left(w_{2 m}, w_{2 m-1}\right) .
$$

Step II. We will show that the theorem with the help of Lemma 1.9. We claim that

$$
d_{1}\left(w_{m+1}, w_{m+2}\right) \leqslant \mathbb{k} d_{1}\left(w_{m}, w_{m+1}\right) \text { for all } m \in N, \text { where } \mathbb{k} \in\left[0, \frac{1}{s}\right) .
$$

We will divide the proof into three cases to establish above inequality. 
Case (1): $M\left(u_{2 m}, u_{2 m-1}\right)=d_{1}\left(w_{2 m}, w_{2 m-1}\right)$.

From (2.3), we have

$$
\psi\left(s^{\epsilon} d_{1}\left(w_{2 m}, w_{2 m+1}\right)\right) \leqslant \psi\left(d_{1}\left(w_{2 m}, w_{2 m-1}\right)\right)-\phi\left(d_{1}\left(w_{2 m}, w_{2 m-1}\right)\right) .
$$

Since $\phi(t)>0$ for $t>0$, we get

$$
\psi\left(s^{\epsilon} d_{1}\left(w_{2 m}, w_{2 m+1}\right)\right) \leqslant \psi\left(d_{1}\left(w_{2 m}, w_{2 m-1}\right)\right) .
$$

By $\psi$ being non-decreasing, we obtain

$$
s^{\epsilon} d_{1}\left(w_{2 m}, w_{2 m+1}\right) \leqslant d_{1}\left(w_{2 m}, w_{2 m-1}\right), \quad d_{1}\left(w_{2 m}, w_{2 m+1}\right) \leqslant \frac{1}{s^{\epsilon}} d_{1}\left(w_{2 m}, w_{2 m-1}\right) .
$$

Take $\mathbb{k}=\frac{1}{\mathrm{~s}^{\mathrm{e}}}$, then $\mathbb{k} \in\left[0, \frac{1}{\mathrm{~s}}\right)$,

$$
\mathrm{d}_{1}\left(w_{2 m}, w_{2 m+1}\right) \leqslant \mathbb{k} d_{1}\left(w_{2 m}, w_{2 m-1}\right) .
$$

Case (2): Taking $M\left(u_{2 m}, u_{2 m-1}\right)=\frac{d_{1}\left(w_{2 m}, w_{2 m+1}\right)+d_{1}\left(w_{2 m}, w_{2 m-1}\right)}{2 s^{\alpha-1}}$ and using (2.4), we have

$$
M\left(u_{2 m}, u_{2 m-1}\right)=\frac{d_{1}\left(w_{2 m}, w_{2 m+1}\right)+d_{1}\left(w_{2 m}, w_{2 m-1}\right)}{2 s^{\alpha-1}} \leqslant \frac{d_{1}\left(w_{2 m-1}, w_{2 m}\right)}{s^{\alpha-1}} \leqslant d_{1}\left(w_{2 m-1}, w_{2 m}\right) .
$$

From (2.3), we obtain

$$
\psi\left(s^{\epsilon} d_{1}\left(w_{2 m}, w_{2 m+1}\right)\right) \leqslant \psi\left(d_{1}\left(w_{2 m}, w_{2 m-1}\right)\right)-\phi\left(\frac{d_{1}\left(w_{2 m}, w_{2 m+1}\right)+d_{1}\left(w_{2 m}, w_{2 m-1}\right)}{2 s^{\alpha-1}}\right) .
$$

Since $\phi(t)>0$ for $t>0$, we have

$$
\psi\left(s^{\epsilon} d_{1}\left(w_{2 m}, w_{2 m+1}\right)\right) \leqslant \psi\left(d_{1}\left(w_{2 m}, w_{2 m-1}\right)\right) .
$$

Also $\psi$ is non-decreasing, therefore

$$
s^{\epsilon} d_{1}\left(w_{2 m}, w_{2 m+1}\right) \leqslant d_{1}\left(w_{2 m}, w_{2 m-1}\right), \quad d_{1}\left(w_{2 m}, w_{2 m+1}\right) \leqslant \frac{1}{s^{\epsilon}} d_{1}\left(w_{2 m}, w_{2 m-1}\right) .
$$

Take, $\mathbb{k}=\frac{1}{\mathrm{~s}^{e}}$, then $\mathbb{k} \in\left[0, \frac{1}{\mathrm{~s}}\right)$.

Case (3): If $M\left(u_{2 m}, u_{2 m-1}\right)=\frac{d_{1}\left(w_{2 m+1}, w_{2 m-1}\right)}{2 s^{\alpha}}$, then by using triangle inequality and (2.4), we can bring again to Case (2). Hence (2.5) holds for all three cases.

Similarly, by taking $\mathrm{Lu}_{2 \mathrm{~m}+1}=w_{2 \mathrm{~m}+1}$ and $\mathrm{Ju}_{2 \mathrm{~m}+2}=w_{2 \mathrm{~m}+2}$, one can easily prove that

$$
\mathrm{d}_{1}\left(w_{2 m+1}, w_{2 m+2}\right) \leqslant \mathbb{k} d_{1}\left(w_{2 m}, w_{2 m+1}\right) .
$$

From the above discussion it is clear that

$$
\mathrm{d}_{1}\left(w_{\mathrm{m}+1}, w_{\mathrm{m}+2}\right) \leqslant \mathbb{k} \mathrm{d}_{1}\left(w_{\mathrm{m}}, w_{\mathrm{m}+1}\right) \text { for } w_{\mathrm{m}} \neq w_{\mathrm{m}+1}, \text { for all } \mathrm{m} \in \mathrm{N} .
$$

Define $d_{k}=d_{1}\left(w_{k}, w_{k+1}\right)$. Suppose $d_{k_{0}}=0$ for some $k_{0}$, then $w_{k_{0}}=w_{k_{0+1}}$. If $k_{0}=2 m$ then $w_{2 m}=w_{2 m+1}$, thus

$$
\begin{aligned}
M\left(u_{2 m}, u_{2 m+1}\right) & \in\left\{0, \frac{d_{1}\left(w_{2 m+1}, w_{2 m+2}\right)+0}{2 s^{\alpha-1}}, \frac{0+d_{1}\left(w_{2 m}, w_{2 m+2}\right)}{2 s^{\alpha}}\right\} \\
& =\left\{0, \frac{d_{1}\left(w_{2 m+2}, w_{2 m+1}\right)}{2 s^{\alpha-1}}, \frac{d_{1}\left(w_{2 m+2}, w_{2 m}\right)}{2 s^{\alpha}}\right\} .
\end{aligned}
$$


We notice that if

$$
M\left(u_{2 m}, u_{2 m+1}\right)=\frac{d_{1}\left(w_{2 m+2}, w_{2 m+1}\right)}{2 s^{\alpha-1}}
$$

by (2.3), we obtain

$$
\psi\left(s^{\epsilon} d_{1}\left(w_{2 m+1}, w_{2 m+2}\right)\right) \leqslant \psi\left(\frac{d_{1}\left(w_{2 m+2}, w_{2 m+1}\right)}{2 s^{\alpha-1}}\right)-\phi\left(\frac{d_{1}\left(w_{2 m+2}, w_{2 m+1}\right)}{2 s^{\alpha-1}}\right) .
$$

Thus

$$
\psi\left(s^{\epsilon} d_{1}\left(w_{2 m+1}, w_{2 m+2}\right)\right) \leqslant \psi\left(\frac{d_{1}\left(w_{2 m+1}, w_{2 m+2}\right)}{2 s^{\alpha-1}}\right) .
$$

Since $\psi$ is non-decreasing, we have

$$
s^{\epsilon} d_{1}\left(w_{2 m+1}, w_{2 m+2}\right) \leqslant \frac{d_{1}\left(w_{2 m+1}, w_{2 m+2}\right)}{2 s^{\alpha-1}}, \quad d_{1}\left(w_{2 m+1}, w_{2 m+2}\right) \leqslant \frac{d_{1}\left(w_{2 m+1}, w_{2 m+2}\right)}{2 s^{\alpha+\epsilon-1}} .
$$

This is only possible in the case in which $d_{1}\left(w_{2 m+1}, w_{2 m+2}\right)=0$. Hence $w_{2 m+1}=w_{2 m+2}$. Thus $w_{2 m}=$ $w_{2 m+1}=w_{2 m+2}$.

Analogously, we can prove the remaining cases.

Consequently, the sequence $\left\{w_{k}\right\}$ is a constant sequence for $k \geqslant k_{0}$. Hence (2.5) also holds for constant sequence.

By (2.5) and Lemma 1.9, we conclude that sequence $\left\{w_{m}\right\}$ is a b-Cauchy. Now, taking into account that a b-Cauchy sequence is convergent and $\mathrm{Y}$ is complete, there exists some $w \in Y$ such that $w_{m} \rightarrow w$. Therefore the following subsequences are also convergent to $w \in Y$. That is $\mathrm{Gu}_{2 \mathrm{~m}} \rightarrow \mathfrak{w}, \mathrm{Hu}_{2 \mathrm{~m}+1} \rightarrow$ $w, \mathrm{Ju}_{2 \mathrm{~m}+1} \rightarrow w$, and $\mathrm{Lu}_{2 \mathrm{~m}} \rightarrow w$.

Step III. We will prove that coincidence point of $G$ and $L$ is $w$. Since

$$
\begin{aligned}
\lim _{m \rightarrow \infty} d_{1}\left(G_{2 m}, w\right) & =\lim _{m \rightarrow \infty} d_{1}\left(J u_{2 m+1}, w\right)=\lim _{m \rightarrow \infty} d_{1}\left(w_{2 m+1}, w\right)=0, \\
\lim _{m \rightarrow \infty} d_{1}\left(H u_{2 m+1}, w\right) & =\lim _{m \rightarrow \infty} d_{1}\left(L u_{2 m+2}, w\right)=\lim _{m \rightarrow \infty} d_{1}\left(w_{2 m+2}, w\right)=0,
\end{aligned}
$$

and $(G, L)$ is compatible, we have

$$
\lim _{m \rightarrow \infty} d_{1}\left(L G u_{2 m}, G L u_{2 m}\right)=0 .
$$

Moreover, $\lim _{m \rightarrow \infty} d_{1}\left(G u_{2 m}, w\right)=0$ and $\lim _{m \rightarrow \infty} d_{1}\left(\operatorname{Lu}_{2 m}, w\right)=0$. Also, $G$ and $L$ are continuous mappings, therefore

$$
\lim _{m \rightarrow \infty} d_{1}\left(L G u_{2 m}, L w\right)=\lim _{m \rightarrow \infty} d_{1}\left(G L u_{2 m}, G w\right)=0
$$

From triangle inequality, one can write

$$
d_{1}(L w, G w) \leqslant s\left(d_{1}\left(L w, L G u_{2 m}\right)+d_{1}\left(L G u_{2 m}, G w\right)\right) .
$$

Again, applying the triangle inequality to the second term of the right hand side, we get

$$
d_{1}(L w, G w) \leqslant s d_{1}\left(L w, L G u_{2 m}\right)+s^{2}\left(d_{1}\left(L_{G u} m, G L u_{2 m}\right)+d_{1}\left(G L u_{2 m}, G w\right)\right) .
$$

Using (2.6) and (2.7) in above inequality and taking limit $\mathrm{m} \rightarrow \infty$, we have

$$
\mathrm{d}_{1}(\mathrm{Lw}, \mathrm{G} w) \leqslant 0 .
$$

Therefore, $\mathrm{d}_{1}(\mathrm{~L} w, \mathrm{G} w)=0$. This implies that $\mathrm{G} w=\mathrm{L} w$. Hence $w$ is coincidence point of $\mathrm{G}$ and $\mathrm{L}$.

Similarly, we can show that $w$ is coincidence point of $\mathrm{H}$ and $\mathrm{J}$. 
Further, if $\mathrm{L} w$ and $J w$ are comparable then by using (2.1), we have

$$
\psi\left(s^{\epsilon} d_{1}(G w, H w)\right) \leqslant \psi(M(w, w))-\phi(M(w, w)),
$$

where

$$
\begin{aligned}
M(w, w) & \in\left\{d_{1}(L w, J w), \frac{d_{1}(L w, G w)+d_{1}(J w, H w)}{2 s^{\alpha-1}}, \frac{d_{1}(L w, H w)+d_{1}(J w, G w)}{2 s^{\alpha}}\right\} \\
& =\left\{d_{1}(G w, H w), 0, \frac{d_{1}(G w, H w)}{s^{\alpha}}\right\} .
\end{aligned}
$$

If $M(w, w)=d_{1}(G w, H w)$, then

$$
\psi\left(s^{\epsilon} d_{1}(G w, H w)\right) \leqslant \psi\left(d_{1}(G w, H w)\right)-\phi\left(d_{1}(G w, H w)\right) .
$$

This is possible if $\mathrm{G} w=\mathrm{H} w$. Hence $w$ is coincidence point of $\mathrm{G}, \mathrm{H}, \mathrm{J}$, and L.

Similarly, for remaining two cases, one can easily prove that $w$ is coincidence point of $G, H$, J, and L. This completes the proof.

In the following theorem we vanish the continuity assumption of $G, H, J$, and $L$ and replace compatibility by weak compatibility.

Theorem 2.2. Let $\mathrm{G}, \mathrm{H}, \mathrm{L}, \mathrm{J}: \mathrm{Y} \rightarrow \mathrm{Y}$ be mappings on a regular partial ordered complete b-metric space $\left(\mathrm{Y}, \preceq, \mathrm{d}_{1}\right)$ such that $\mathrm{G}(\mathrm{Y}) \subseteq \mathrm{J}(\mathrm{Y}), \mathrm{H}(\mathrm{Y}) \subseteq \mathrm{L}(\mathrm{Y})$, and $\mathrm{J}(\mathrm{Y})$ and $\mathrm{L}(\mathrm{Y})$ are $\mathrm{b}$-closed subsets of $\mathrm{Y}$. Assume that for $\epsilon>1$ the weakly compatible pairs $(\mathrm{G}, \mathrm{L})$ and $(\mathrm{H}, \mathrm{J})$ satisfy the following contraction condition

$$
\psi\left(s^{\epsilon} d_{1}(G u, H w)\right) \leqslant \psi(M(u, w))-\phi(M(u, w)) \text { for all } u, w \in Y,
$$

whenever $\phi, \psi:[0, \infty) \rightarrow[0, \infty)$ are altering distance functions. Suppose that the pairs $(G, H)$ and $(H, G)$ are partially weakly increasing with respect to $\mathrm{J}$ and $\mathrm{L}$, respectively, then the pairs $(\mathrm{G}, \mathrm{L})$ and $(\mathrm{H}, \mathrm{J})$ have a coincidence point. Further, if $\mathrm{L} w$ and $\mathrm{Jw}$ are comparable then $w$ is coincidence point of $\mathrm{G}, \mathrm{H}, \mathrm{J}$, and $\mathrm{L}$.

Proof. By following the proof of Theorem 2.1, we conclude that for a sequence $\left\{w_{m}\right\}$ there exists $w \in Y$, such that

$$
\lim _{m \rightarrow \infty} d_{1}\left(w_{m}, w\right)=0
$$

Since $L(Y), J(Y)$ are b-closed subsets of $Y$, then for $\left\{w_{2 m+1}\right\} \subseteq J(Y),\left\{w_{2 m+2}\right\} \subseteq L(Y)$ there exist $x, y \in Y$, such that $w=J x$ and $w=L y$. Therefore

$$
\lim _{m \rightarrow \infty} J u_{2 m+1}=\lim _{m \rightarrow \infty} w_{2 m+1}=w=L y, \quad \lim _{m \rightarrow \infty} H u_{2 m+1}=\lim _{m \rightarrow \infty} w_{2 m+2}=w=L y .
$$

We will show that $G$ and $L$ have a coincidence point $w$. Since $J u_{2 m+1} \preceq$ Ly and $H u_{2 m+1} \preceq$ Ly, by using regularity of partial ordered complete b-metric space $\left(Y, \preceq, d_{1}\right)$ and $(2.8)$, we have

$$
\psi\left(s^{\epsilon} d_{1}\left(G y, H u_{2 m+1}\right)\right) \leqslant \psi\left(M\left(y, u_{2 m+1}\right)\right)-\phi\left(M\left(y, u_{2 m+1}\right)\right),
$$

where

$$
\begin{aligned}
& M\left(y, u_{2 m+1}\right) \\
& \in\left\{d_{1}\left(L y, J u_{2 m+1}\right), \frac{d_{1}(L y, G y)+d_{1}\left(J u_{2 m+1}, H u_{2 m+1}\right)}{2 s^{\alpha-1}}, \frac{d_{1}\left(L y, H u_{2 m+1}\right)+d_{1}\left(J u_{2 m+1}, G y\right)}{2 s^{\alpha}}\right\} \\
& \leqslant\left\{d_{1}\left(L y, J u_{2 m+1}\right), \frac{d_{1}(L y, G y)+d_{1}\left(J u_{2 m+1}, H u_{2 m+1}\right)}{2 s^{\alpha-1}}, \frac{d_{1}\left(L y, H u_{2 m+1}\right)}{2 s^{\alpha}}\right.
\end{aligned}
$$




$$
\begin{aligned}
& \left.+\frac{d_{1}\left(J u_{2 m+1}, L y\right)+d_{1}(L y, G y)}{2 s^{\alpha-1}}\right\} \\
\leqslant & \left\{0, \frac{d_{1}(L y, G y)}{2 s^{\alpha-1}}, \frac{d_{1}(L y, G y)}{2 s^{\alpha-1}}\right\} .
\end{aligned}
$$

Using (2.10) in (2.9), one has

$$
\begin{aligned}
\psi\left(s^{\epsilon} d_{1}(G y, L y)\right) & \leqslant \psi\left(\frac{d_{1}(L y, G y)}{2 s^{\alpha-1}}\right)-\phi\left(\frac{d_{1}(L y, G y)}{2 s^{\alpha-1}}\right) \\
& \leqslant \psi\left(2 s^{\epsilon+\alpha-1} \frac{d_{1}(L y, G y)}{2 s^{\alpha-1}}\right)-\phi\left(\frac{d_{1}(L y, G y)}{2 s^{\alpha-1}}\right)=\psi\left(s^{\epsilon} d_{1}(L y, G y)\right)-\phi\left(\frac{d_{1}(L y, G y)}{2 s^{\alpha-1}}\right) .
\end{aligned}
$$

This is only possible if $d_{1}(L y, G y)=0$. It implies that $L y=G y$. Hence $w=L y=G y$. Now from compatibility of $\mathrm{G}$ and $\mathrm{L}$, we can write $\mathrm{G} w=\mathrm{GLy}=\mathrm{LGy}=\mathrm{L} w$. Hence $w$ is coincidence point of $\mathrm{G}$ and L.

Similarly, we can show that $w$ is coincidence point of $\mathrm{H}$ and $\mathrm{J}$. The remaining proof is the same as the proof of Theorem 2.1 and therefore we omit it.

From above theorems one can easily prove the following corollaries.

By taking $J=I$ (the identity mapping of $Y$ ) in Theorem 2.2 and for all $u, w \in Y$ and $\alpha \geqslant 1$,

$$
M(u, w) \in\left\{d_{1}(L u, w), \frac{d_{1}(L u, G u)+d_{1}(w, H w)}{2 s^{\alpha-1}}, \frac{d_{1}(L u, H w)+d_{1}(w, G u)}{2 s^{\alpha}}\right\},
$$

we have the following common fixed point result for three mappings.

Corollary 2.3. Let $\mathrm{G}, \mathrm{H}, \mathrm{L}: \mathrm{Y} \rightarrow \mathrm{Y}$ be mappings on regular partial ordered complete b-metric space $\left(\mathrm{Y}, \preceq, \mathrm{d}_{1}\right)$ such that $\mathrm{G}(\mathrm{Y}) \subseteq \mathrm{Y}$ and $\mathrm{H}(\mathrm{Y}) \subseteq \mathrm{L}(\mathrm{Y})$. Assume that for $\epsilon>1$ the weakly compatible pairs $(\mathrm{G}, \mathrm{L})$ and $(\mathrm{H}, \mathrm{J})$ satisfy the contractive condition

$$
\psi\left(s^{\epsilon} d_{1}(G u, H w)\right) \leqslant \psi(M(u, w))-\phi(M(u, w)) \text { for all } u, w \in Y,
$$

whenever $\phi, \psi:[0, \infty) \rightarrow[0, \infty)$ are altering distance functions. Further, we assume that pairs $(G, H)$ and $(H, G)$ are partially weakly increasing and partially weakly increasing with respect to $\mathrm{L}$, respectively. If $\mathrm{L} w$ and $w$ are comparable then $w$ is coincidence point of $\mathrm{G}, \mathrm{H}$, and $\mathrm{L}$.

By setting $\mathrm{L}=\mathrm{J}$ in Theorem 2.1 with

$$
M(u, w) \in\left\{d_{1}(J u, J w), \frac{d_{1}(J u, G u)+d_{1}(J w, H w)}{2 s^{\alpha-1}}, \frac{d_{1}(J u, H w)+d_{1}(J w, G u)}{2 s^{\alpha}}\right\},
$$

we have the following corollary.

Corollary 2.4. Let $\mathrm{G}, \mathrm{H}, \mathrm{J}: \mathrm{Y} \rightarrow \mathrm{Y}$ be mappings on a partial ordered complete $\mathrm{b}$-metric space $\left(\mathrm{Y}, \preceq, \mathrm{d}_{1}\right)$ such that $\mathrm{G}(\mathrm{Y}) \cup \mathrm{H}(\mathrm{Y}) \subseteq \mathrm{J}(\mathrm{Y})$ where $\mathrm{J}(\mathrm{Y})$ is continuous. Let $(\mathrm{G}, \mathrm{H})$ be a partially weakly increasing pair with respect to $\mathrm{J}$. Further, we assume that one of the following conditions are true

(i) $\mathrm{G}$ is continuous and $(\mathrm{G}, \mathrm{J})$ is compatible;

(ii) $\mathrm{H}$ is continuous and $(\mathrm{H}, \mathrm{J})$ is compatible.

If for altering distance functions $\phi, \psi:[0, \infty) \rightarrow[0, \infty)$ the following condition holds

$$
\psi\left(s^{\epsilon} d_{1}(G u, H w)\right) \leqslant \psi(M(u, w))-\phi(M(u, w)) \text { for all } u, w \in Y,
$$

whenever $\epsilon>1$, then $\mathrm{G}, \mathrm{H}$, and $\mathrm{J}$ have a coincidence point. 
By setting $L=J$ and $G=H$ in Theorem 2.1 with

$$
M(u, w) \in\left\{d_{1}(J u, J w), \frac{d_{1}(J u, G u)+d_{1}(J w, G w)}{2 s^{\alpha-1}}, \frac{d_{1}(J u, G w)+d_{1}(J w, G u)}{2 s^{\alpha}}\right\},
$$

we arrive to the following corollary.

Corollary 2.5. Let $\mathrm{G}, \mathrm{J}: \mathrm{Y} \rightarrow \mathrm{Y}$ be mappings on a partial ordered complete $\mathrm{b}$-metric space $\left(\mathrm{Y}, \preceq, \mathrm{d}_{1}\right)$ such that $\mathrm{G}(\mathrm{Y}) \subseteq \mathrm{J}(\mathrm{Y})$ where $\mathrm{J}$ and $\mathrm{G}$ are continuous. Let us take $\mathrm{G}$ partially weakly increasing with respect to $\mathrm{J}$ and let $(\mathrm{G}, \mathrm{J})$ be compatible. If for altering distance functions $\phi, \psi:[0, \infty) \rightarrow[0, \infty)$ the following condition holds

$$
\psi\left(s^{\epsilon} d_{1}(G u, G w)\right) \leqslant \psi(M(u, w))-\phi(M(u, w)) \text { for all } u, w \in Y,
$$

whenever $\epsilon>1$, then $\mathrm{G}$ and $\mathrm{J}$ have a coincidence point.

By setting $L=J$ in Theorem 2.2 with

$$
M(u, w) \in\left\{d_{1}(J u, J w), \frac{d_{1}(J u, G u)+d_{1}(J w, H w)}{2 s^{\alpha-1}}, \frac{d_{1}(J u, H w)+d_{1}(J w, G u)}{2 s^{\alpha}}\right\},
$$

we have the following.

Corollary 2.6. Let $\mathrm{G}, \mathrm{H}, \mathrm{J}: \mathrm{Y} \rightarrow \mathrm{Y}$ be mappings on a regular partial ordered complete $\mathrm{b}$-metric space $\left(\mathrm{Y}, \preceq, \mathrm{d}_{1}\right)$ such that $\mathrm{G}(\mathrm{Y}) \cup \mathrm{H}(\mathrm{Y}) \subseteq \mathrm{J}(\mathrm{Y})$ where $\mathrm{J}(\mathrm{Y})$ is complete subset of $\mathrm{Y}$. Let us take partially weakly increasing pair $(\mathrm{G}, \mathrm{H})$ with respect to $\mathrm{J}$ and let $(\mathrm{G}, \mathrm{J}),(\mathrm{H}, \mathrm{J})$ be weakly compatible pairs. If for altering distance functions $\phi, \psi:[0, \infty) \rightarrow[0, \infty)$ the following condition holds

$$
\psi\left(s^{\epsilon} d_{1}(G u, H w)\right) \leqslant \psi(M(u, w))-\phi(M(u, w)) \text { for all } u, w \in Y,
$$

whenever $\epsilon>1$, then $\mathrm{G}, \mathrm{H}$, and $\mathrm{J}$ have a coincidence point.

By setting $L=J$ and $G=H$ in Theorem 2.2 with

$$
M(u, w) \in\left\{d_{1}(J u, J w), \frac{d_{1}(J u, G u)+d_{1}(J w, G w)}{2 s^{\alpha-1}}, \frac{d_{1}(J u, G w)+d_{1}(J w, J u)}{2 s^{\alpha}}\right\},
$$

then one can get the following corollary.

Corollary 2.7. Let us take mappings $\mathrm{G}, \mathrm{J}: \mathrm{Y} \rightarrow \mathrm{Y}$ on a regular partial ordered complete b-metric space $\left(\mathrm{Y}, \preceq, \mathrm{d}_{1}\right)$ such that $\mathrm{G}(\mathrm{Y}) \subseteq \mathrm{J}(\mathrm{Y})$. Let us take $\mathrm{G}$ partially weakly increasing with respect to $\mathrm{J}$ and let $(\mathrm{G}, \mathrm{J})$ be weakly compatible. If for altering distance functions $\phi, \psi:[0, \infty) \rightarrow[0, \infty)$ the following condition holds

$$
\psi\left(s^{\epsilon} d_{1}(G u, G w)\right) \leqslant \psi(M(u, w))-\phi(M(u, w)) \text { for all } u, w \in Y,
$$

whenever $\epsilon>1$, then $\mathrm{G}$ and $\mathrm{J}$ have a coincidence point.

By setting $\mathrm{L}=\mathrm{J}=\mathrm{I}$ (the identity mapping) in Theorem 2.1 then

$$
M(u, w) \in\left\{d_{1}(u, w), \frac{d_{1}(u, G u)+d_{1}(w, H w)}{2 s^{\alpha}}, \frac{d_{1}(u, H w)+d_{1}(w, G u)}{2 s^{\alpha-1}}\right\},
$$

one has the following result.

Corollary 2.8. Let $\mathrm{G}, \mathrm{H}: \mathrm{Y} \rightarrow \mathrm{Y}$ be two mappings on a partial ordered complete b-metric space $\left(\mathrm{Y}, \preceq, \mathrm{d}_{1}\right)$. Let us take partially weakly increasing pair $(\mathrm{G}, \mathrm{H})$ and either,

(i) $\mathrm{G}$ or $\mathrm{H}$ is continuous; or 
(ii) $\mathrm{Y}$ is regular.

If for altering distance functions $\phi, \psi:[0, \infty) \rightarrow[0, \infty)$ the following condition holds

$$
\psi\left(s^{\epsilon} d_{1}(G u, G w)\right) \leqslant \psi(M(u, w))-\phi(M(u, w)) \text { for all } u, w \in Y,
$$

whenever $\epsilon>1$, then $\mathrm{G}$ and $\mathrm{H}$ have a common fixed point in $\mathrm{Y}$.

Example 2.9. Let us define partial ordering $\preceq$ on $Y=[0, \infty)$ as follows:

$$
u \preceq w \text { if and only if } w \leqslant u \text { for all } u, w \in Y .
$$

Let $d_{1}(u, w)=|u-w|^{3}$ for all $u, w \in Y$. Then, $d_{1}$ is a partial order b-metric on $Y$ with $s=4$. Suppose $\mathrm{G}, \mathrm{H}, \mathrm{J}$, and $\mathrm{L}$ are continuous mappings defined as follows:

$$
\mathrm{G}(\mathrm{u})=\sinh ^{-1} \mathrm{u}, \quad \mathrm{H}(\mathrm{u})=\sinh ^{-1} \frac{\mathrm{u}}{2}, \quad J(u)=\sinh 2 u, \quad L(u)=\sinh 4 u .
$$

Clearly, the pairs $(G, L)$ and $(H, J)$ are compatible. If $\left\{u_{m}\right\}$ is a sequence in $Y$ such that for some $v \in Y$

$$
\lim _{m \rightarrow \infty} d_{1}\left(v, G u_{m}\right)=\lim _{m \rightarrow \infty} d_{1}\left(v, L u_{m}\right)=0,
$$

then we have

$$
\lim _{m \rightarrow \infty}\left|\sinh ^{-1} u_{m}-v\right|^{3}=\lim _{m \rightarrow \infty}\left|\sinh 4 u_{m}-v\right|^{3}=0 .
$$

Since $\mathrm{G}$ and $\mathrm{L}$ are continuous, one can write

$$
\lim _{m \rightarrow \infty}\left|u_{m}-\sinh v\right|^{3}=\lim _{v \rightarrow \infty}\left|u_{m}-\frac{\sinh ^{-1} v}{4}\right|^{3}=0 .
$$

Thus $\sinh v=\frac{\sinh ^{-1} v}{4}$ if and only if $v=0$. By the continuity of $G$ and $L$, we obtain

$$
\lim _{m \rightarrow \infty} d_{1}\left(G L u_{m}, L G u_{m}\right)=\lim _{m \rightarrow \infty}\left|G L u_{m}-L G u_{m}\right|^{3}=0 .
$$

This assures the compatibility of $(G, L)$ pair. Similarly, we can show the compatibility of $(H, J)$.

Next, we shall show that pair $(G, H)$ is partially weakly increasing with respect to J. Let $w \in J^{-1}(G u)$, for $u, w \in Y$

$$
\mathrm{G}(\mathrm{u})=\mathrm{J}(w) \Rightarrow \sinh ^{-1} \mathrm{u}=\sinh 2 w .
$$

Therefore $w=\frac{\sinh ^{-1}\left(\sinh ^{-1} u\right)}{2}$. Since we know that

$$
\sinh u \geqslant \sinh ^{-1} u \Rightarrow u \geqslant \sinh ^{-1}\left(\sinh ^{-1} u\right)
$$

it follows $u \geqslant \frac{\sinh ^{-1}\left(\sinh ^{-1} u\right)}{2}$. On the other hand, we have

$$
\mathrm{G}(\mathrm{u})=\sinh ^{-1} \mathrm{u} \geqslant \sinh ^{-1}\left(\frac{\sinh ^{-1}\left(\sinh ^{-1} \mathrm{u}\right)}{2}\right)=\sinh ^{-1} w=\mathrm{H} w,
$$

thus $\mathrm{G}(\mathrm{u}) \geqslant \mathrm{H}(w)$, therefore $\mathrm{G}(\mathrm{u}) \preceq \mathrm{H}(\boldsymbol{w})$.

Similarly, we can show that the pair $(H, G)$ is partially weakly increasing with respect to $L$.

Now, we show that $\psi\left(s^{\epsilon} d_{1}(G u, H w)\right) \leqslant \psi(M(u, w))-\phi(M(u, w))$ for all $u, w \in Y$. Here $M(u, w)$ is defined previously, where $\psi(v)=b v, \phi(v)=(b-1) v, 1<b \leqslant 2$ and take $1<\epsilon<\frac{5}{2}$. Take

Using mean value theorem for the functions $\sinh ^{-1}$ and $\sinh$ on the intervals $\left[u, \frac{w}{2}\right]$ and $[4 u, 2 w] \subset Y$.

$$
\psi\left(4^{\epsilon} \mathrm{d}_{1}(\mathrm{Gu}, \mathrm{H} w)\right)=4^{\epsilon} \mathrm{b}|\mathrm{Gu}-\mathrm{H} w|^{3}
$$




$$
\begin{aligned}
& \leqslant 4^{\epsilon} \mathrm{b}\left|\sinh ^{-1} u-\sinh ^{-1} \frac{w}{2}\right|^{3} \\
& \leqslant 4^{\epsilon} \mathrm{b}\left|\mathrm{u}-\frac{w}{2}\right|^{3} \\
& \leqslant 4^{\epsilon} \mathrm{b} \frac{|4 u-2 w|^{3}}{4^{3}} \\
& \leqslant 4^{\epsilon-3} \mathrm{~b}|\sinh 4 u-\sinh 2 w|^{3} \\
& =4^{\epsilon-3} \mathrm{~b}|\mathrm{Lu}-\mathrm{Jw}|^{3} \\
& \leqslant \mathrm{~d}_{1}(\mathrm{Lu}, \mathrm{Jw}) \\
& =\psi(M(u, w))-\phi(M(u, w)) .
\end{aligned}
$$

Hence all conditions of Theorem 2.1 are satisfied and 0 is coincidence point of these four mappings.

Remark 2.10. For Example 3 of [20] it is easy to see that all conditions of our Theorem 2.1 are satisfied and hence the corresponding conclusions holds. However, if $1<\epsilon<\frac{5}{2}$, then condition (1.1) of Theorem 1.10 does not hold for Example 2.9 but our condition (2.1) holds, therefore our Theorem 2.1 is a genuine generalization of Theorem 1.10.

Remark 2.11. By taking $\epsilon=4$ and $\alpha=2$ in our results, it is easy to handle the results of [20].

\section{Application to the system of non-linear integral equations}

We consider the following system of integral equations

$$
\left\{\begin{array}{l}
x(a)=F(a)+\int_{t}^{r} K_{1}(a, v, x(v)) d_{1} v \\
x(a)=F(a)+\int_{t}^{r} K_{2}(a, v, x(v)) d_{1} v, \\
x(a)=F(a)+\int_{t}^{r} K_{3}(a, v, x(v)) d_{1} v,
\end{array}\right\}
$$

where $K_{1}, K_{2}, K_{3}:[t, r] \times[t, r] \times \mathbb{R} \rightarrow \mathbb{R}$.

Let $G, H, L: Y \rightarrow Y$ and $F:[t, r] \rightarrow \mathbb{R}$ be continuous mappings. We redefine above system of integral equation as:

$$
\left\{\begin{array}{l}
\mathrm{G}(x(a))=F(a)+\int_{t}^{r} K_{1}(a, v, x(v)) d_{1} v, \\
H(x(a))=F(a)+\int_{t}^{r} K_{2}(a, v, x(v)) d_{1} v, \\
L(x(a))=F(a)+\int_{t}^{r} K_{3}(a, v, x(v)) d_{1} v
\end{array}\right\}
$$

for all $x \in Y$ and $a, v \in[t, r]$. Clearly, by using Corollary 2.3, the existence of solution to (3.1) that belongs to $Y=C[t, r]$ is equivalent to the existence of a common fixed point of $G, H$, and $L$.

We define a partial ordering on $Y$ as follows: $x \preceq y$ if and only if $x(a) \leqslant y(a)$ and we define a $b$-metric on $Y$ as follows: $d_{1}(x(a), y(a))=\max _{a \in[t, r]}|x(a)-y(a)|^{p}$ for all $x, y \in Y$.

Theorem 3.1. Suppose that the following conditions are satisfied:

(i) $\mathrm{K}_{1}, \mathrm{~K}_{2}, \mathrm{~K}_{3}:[\mathrm{t}, \mathrm{r}] \times[\mathrm{t}, \mathrm{r}] \times \mathbb{R} \rightarrow \mathbb{R}$ are continuous;

(ii) for all $a, v \in[t, r]$ and $x \in Y$ we have,

$$
K_{1}(a, v, x(v)) \leqslant K_{2}\left(a, v, \int_{t}^{r} K_{1}(a, v, x(v)) d v+F(a)\right),
$$




$$
K_{2}(a, v, x(v)) \leqslant K_{1}(a, v, y(v)) \text { for all } K_{3}(a, v, y(v))=K_{2}(a, v, x(v)),
$$

and

$$
K_{1}\left(a, v, \int_{t}^{r} K_{3}(a, v, x(v)) d v+F(a)\right)=K_{3}\left(a, v, \int_{t}^{r} K_{1}(a, v, x(v)) d v+F(a)\right) ;
$$

(iii) for all $\mathrm{a}, v \in[\mathrm{t}, \mathrm{r}]$ and $\mathrm{x}, \mathrm{y} \in \mathrm{Y}$ with $\mathrm{x} \preceq \mathrm{y}$ we have

$$
\left|K_{3}(a, v, x(v))-K_{2}(a, v, y(v))\right|^{p} \leqslant R(a, v) \ln \left(1+|\operatorname{Lx}(v)-y(v)|^{p}\right),
$$

where $\mathrm{R}$ is a continuous function satisfying the condition

$$
\sup _{a \in[t, r]} \int_{t}^{r} R(a, v) d_{1} v<\frac{1}{(2)^{p \epsilon}(r-t)^{p-1}} .
$$

Then system (3.1) of nonlinear integral equation has a unique solution.

Proof. Clearly, by condition (ii), the pair $(\mathrm{G}, \mathrm{H})$ is partially weakly increasing and

$$
H(x(a))=F(a)+\int_{t}^{r} K_{2}(a, v, x(v)) d_{1} v \leqslant F(a)+\int_{t}^{r} K_{1}(a, v, y(v)) d_{1} v=G(y(a))
$$

for all $K_{3}(a, v, y(v))=K_{2}(a, v, x(v))$. Hence, $H(x(a)) \leqslant G(y(a))$.

$$
\mathrm{F}(\mathrm{a})+\int_{\mathrm{t}}^{r} \mathrm{~K}_{3}(\mathrm{a}, v, y(v))=\mathrm{F}(\mathrm{a})+\int_{\mathrm{t}}^{\mathrm{r}} \mathrm{K}_{2}(\mathrm{a}, v, x(v)) \Rightarrow \mathrm{L} y(\mathrm{a})=\mathrm{H} x(\mathrm{a}) .
$$

Therefore, $G y(a) \preceq H x(a)$ for all $y(a) \in L^{-1} H x(a)$. So $(H, G)$ is partially weakly increasing pair with respect to L. Also from condition (ii) the pair $(G, L)$ is weakly compatible. Let $1 \leqslant p, q<\infty$ with $\frac{1}{p}+\frac{1}{q}=1$. From condition (iii) for all $a \in[t, r]$, we have

$$
\begin{aligned}
2^{p \epsilon}|\mathrm{G}(x(a))-H(y(a))|^{p} & \leqslant 2^{p \epsilon}\left[\left|\int_{t}^{r} K_{1}(a, v, x(v)) d_{1} v-\int_{t}^{r} K_{2}(a, v, y(v)) d_{1} v\right|^{p}\right], \\
& \leqslant 2^{p \epsilon \epsilon}\left[\left|\int_{t}^{r} K_{3}(a, v, x(v)) d_{1} v-\int_{t}^{r} K_{2}(a, v, y(v)) d_{1} v\right|^{p}\right], \\
& \leqslant 2^{p \epsilon \epsilon}\left[\left(\left|\int_{t}^{r}(1)\left(K_{3}(a, v, x(v))-K_{2}(a, v, y(v))\right)\right| d_{1} v\right)^{p}\right], \\
& \leqslant 2^{p \epsilon}\left[\left(\left(\int_{t}^{r} 1^{q} d_{1} s\right)^{\frac{1}{q}}\right)^{p}\left(\left(\int_{t}^{r}\left|K_{3}(a, v, x(v))-K_{2}(a, v, y(v))\right|^{p} d_{1} v\right)^{\frac{1}{p}}\right)^{p}\right] \\
& \leqslant 2^{p \epsilon}(r-t)^{\frac{p}{q}} \int_{t}^{r} R(a, v) \ln \left(1+|\operatorname{Lx}(v)-y(v)|^{p} d_{1} v\right), \\
& \leqslant 2^{p \epsilon}(r-t)^{p-1} \int_{t}^{r} R(a, v) d_{1} v\left(\ln \left(1+d_{1}(\operatorname{Lx}(v), y(v))\right),\right. \\
& \leqslant \ln (1+M(x, y)) .
\end{aligned}
$$

Hence,

$$
s^{\epsilon} d_{1}(G(x), H(y)) \leqslant M(x, y)-[M(x, y)-\ln (1+M(x, y))] .
$$

Define $\psi(z)=z$ and $\phi(z)=z-\ln (1+z)$, where $s=2^{\mathrm{P}}$. Thus

$$
\psi\left(s^{\epsilon} d_{1}(G(x), H(y))\right) \leqslant \psi(M(x, y))-\phi(M(x, y)) .
$$

Hence by Corollary 2.3 system (3.2) has a solution. Consequently, (3.1) has a solution in Y. 


\section{Acknowledgment}

This work was supported by the National Natural Science Foundation of China (11571378).

The authors are also grateful to the editor and anonymous reviewers for their careful reviews, valuable comments and remarks to improve this manuscript.

\section{References}

[1] M. Abbas, D. Dorić, Common fixed point for generalized $(\Psi, \Phi)$-weak contractions, Math. Un. of Nis. Serbia., 10 (2010), $1-10.1$

[2] M. Abbas, T. Nazir, S. Radenović, Common fixed points of four maps in partially ordered metric spaces, Appl. Math. Lett., 24 (2011), 1520-1526. 1.1

[3] A. Aghajani, M. Abbas, J. R. Roshan, Common fixed point of generalized weak contractive mappings in partially ordered b-metric spaces, Math. Slovaca, 64 (2014), 941-960. 1

[4] R. Allahyari, R. Arab, A. Shole Haghighi, A generalization on weak contractions in partially ordered b-metric spaces and its application to quadratic integral equations, J. Inequal. Appl., 2014 (2014), 15 pages. 1

[5] I. Altun, H. Simsek, Some fixed point theorems on ordered metric spaces and application, Fixed Point Theory Appl., 2010 (2010), 17 pages. $1.6,1.7$

[6] S. Czerwik, Nonlinear set-valued contraction mappings in b-metric spaces, Atti Sem. Mat. Fis. Univ. Modena, 46 (1998), 263-276. 1.5

[7] D. Dorić, Common fixed point for generalized ( $\psi, \phi)$-weak contractions, Appl. Math. Lett., 22 (2009), 1896-1900. 1

[8] P. N. Dutta, B. S. Choudhury, A generalisation of contraction principle in metric spaces, Fixed Point Theory Appl., 18 (2008), 8 pages. 1

[9] J. Esmaily, S. M. Vaezpour, B. E. Rhoades, Coincidence point theorem for generalized weakly contractions in ordered metric spaces, Appl. Math. Comput., 219 (2012), 1536-1548. 1.2

[10] M. Jovanović, Z. Kadelburg, S. Radenović, Common fixed point results in metric-type spaces, Fixed Point Theory Appl., 2010 (2010), 15 pages. 1.9

[11] G. Jungck, Compatible mappings and common fixed points, Internat. J. Math. Math. Sci., 4 (1986), 771-779. 1.3

[12] G. Jungck, Common fixed points for noncontinuous nonself maps on nonmetric spaces, Far East J. Math. Sci., 4 (1996), 199-215. 1.4

[13] P. P. Murthy, K. Tas, U. Devi Patel, Common fixed point theorems for generalized $(\phi, \psi)$-weak contraction condition in complete metric spaces, J. Inequal. Appl., 2015 (2015), 14 pages. 1

[14] H. K. Nashine, B. Samet, Fixed point results for mappings satisfying $(\psi, \phi)$-weakly contractive condition in partially ordered metric spaces, Nonlinear Anal., 74 (2011), 2201-2209. 1, 1.2

[15] S. Radenović, Z. Kadelburg, Generalized weak contractions in partially ordered metric spaces, Comput. Math. Appl., 60 (2010), 1776-1783. 1

[16] A. C. M. Ran, M. C. B. Reurings, A fixed point theorem in partially ordered sets and some applications to matrix equations, Proc. Amer. Math. Soc., 132 (2004), 1435-1443. 1

[17] K. P. R. Rao, I. Altun, K. R. K. Rao, N. Srinivasarao, A common fixed point theorem for four maps under $(\psi, \phi)$ contractive condition of integral type in ordered partial metric spaces, Math. Sci. Lett., 4 (2015), 25-31. 1

[18] A. Razani, V. Parvaneh, M. Abbas, A common fixed point for generalized $(\psi, \phi)_{\mathrm{f}, \mathrm{g}}$-weak contractions, Ukrainian Math. J., 63 (2012), 1756-1769. 1

[19] J. R. Roshan, V. Parvaneh, I. Altun, Some coincidence point results in ordered b-metric spaces and applications in a system of integral equations, Appl. Math. Comput., 226 (2014), 725-737. 1

[20] J. R. Roshan, V. Parvaneh, S. Radenović, M. Rajović, Some coincidence point results for generalized $(\psi, \varphi)$-weakly contractions in ordered b-metric spaces, Fixed Point Theory Appl., 2015 (2015), 21 pages. 1.8, 1, 2.10, 2.11

[21] J. R. Roshan, V. Parvaneh, S. Sedghi, N. Shobkolaei, W. Shatanawi, Common fixed points of almost generalized $(\psi, \varphi)_{\mathrm{S}^{-}}$ contractive mappings in ordered b-metric spaces, Fixed Point Theory Appl., 2013 (2013), 23 pages. 1

[22] W. Shatanawi, B. Samet, On $(\psi, \phi)$-weakly contractive condition in partially ordered metric spaces, Comput. Math. Appl., 62 (2011), 3204-3214. 1 